\title{
Molecular Cloning and Characterization of Plastin, a Human Leukocyte Protein Expressed in Transformed Human Fibroblasts
}

\author{
CHING-SHWUN LIN, ${ }^{1 *}$ RUEDI H. AEBERSOLD,${ }^{2}$ STEPHEN B. KENT, ${ }^{2}$ MADHU VARMA, ${ }^{1}$ \\ AND JOHN LEAVITT ${ }^{1}$ \\ Institute for Medical Research, 2260 Clove Drive, San Jose, California 95128, ${ }^{1}$ and Division of Biology, \\ California Institute of Technology, Pasadena, California $91125^{2}$
}

Received 14 June 1988/Accepted 5 August 1988

\begin{abstract}
The phosphoprotein plastin was originally identified as an abundant transformation-induced polypeptide of chemically transformed neoplastic human fibroblasts. This abundant protein is normally expressed only in leukocytes, suggesting that it may play a role in hemopoietic cell differentiation. Protein microsequencing of plastin purified from leukemic $\mathbf{T}$ lymphocytes by high-resolution two-dimensional gel electrophoresis produced eight internal oligopeptide sequences. An oligodeoxynucleotide probe corresponding to one of the oligopeptides was used to clone cDNAs from transformed human fibroblasts that encoded the seven other oligopeptides predicted for human plastin. Sequencing and characterization of two cloned cDNAs revealed the existence of two distinct, but closely related, isoforms of plastin-l-plastin, which is expressed in leukocytes and transformed fibroblasts, and t-plastin, which is expressed in normal cells of solid tissues and transformed fibroblasts. The leukocyte isoform I-plastin is expressed in a diverse variety of human tumor cell lines, suggesting that it may be involved in the neoplastic process of some solid human tumors.
\end{abstract}

The importance of oncogenes in the development of human cancer has been amply demonstrated in recent years by the ability of these genes to cause tumorigenic conversion of rodent cells. There can be no doubt that other human genes exist which are not classified as oncogenes per se but which play important roles in the development and progression of cancer. One category of these genes encodes abundant structural proteins such as the actins and tropomyosins. The involvement of these abundant proteins in the neoplastic transformation process is suggested by the well-documented observations that isoforms within these structural protein families are consistently modulated in the transformation of avian $(16,38)$, rodent $(6,9,19,28)$, and human $(19,21,23$, $24)$ cells. This second category of cancer-related genes is set apart from the so-called oncogenes because modulation of these genes in a transformation-sensitive manner is likely to result from regulatory processes activating transcription or translation rather than from direct activation through mutational processes $(5,36)$.

Previously, we examined the abundant proteins synthesized in normal and transformed human fibroblasts by means of comparative high-resolution two-dimensional (2-D) polyacrylamide gel electrophoresis and identified an abundant phosphorylated polypeptide, plastin (p219/p220 [20]; $M_{\mathrm{r}}$, 68,$000 ; \mathrm{pI} 5.3$ ), that is frequently expressed in human cancer cells of solid tissue but that is not expressed in normal human fibroblasts $(13,14,20,22,23)$. When we examined proteins of normal peripheral blood leukocytes, we found that the same protein was one of the most abundant constitutively expressed proteins of leukocytes (13). Cross identification of plastin in the transformed fibroblasts and leukocytes was based upon the finding that the protein identified as plastin in mixed proteins of the two cell types comigrated in a 2-D gel as a single spot. Furthermore, two separate peptide antibodies specific for the amino acid sequence around residue 244 of actin cross-reacted with plastin from

\footnotetext{
* Corresponding author.
}

either transformed fibroblasts or lymphocytes in a 2-D gel Western blot (immunoblot) (37).

Goldman and colleagues $(12,20)$ observed that plastin (p301 [12] or p219/p220 [20]) was polymorphic in charge among 28 individuals whose leukocyte proteins were examined by 2-D gel electrophoresis. They later referred to this protein as NIMH4 and NC4 $(10,11)$. Together we determined that NIMH4 (or NC4) and 1-plastin of fibroblasts were the same polypeptide (20). Later, Goldstein et al. also reported that l-plastin was polymorphic in human leukocytes (13). Independently, Kondo and Hamaguchi (18) used the polymorphic character of plastin (LCP1, NIMH4, NC4, or p219/p220) in a gene segregation analysis to link the l-plastin gene to the esterase $\mathrm{D}$ and retinoblastoma loci on human chromosome 13. This linkage of the plastin gene to the esterase $D$ gene has been supported in a separate gene segregation study by Goldman (David Goldman, National Institute of Alcohol and Drug Abuse, Bethesda, Md., personal communication). Despite the reproducible identification of plastin and these studies of its expression and polymorphic character, nothing was known of its molecular identity.

To study the cellular function of plastin and the mechanisms controlling plastin gene expression, we attempted to clone the cDNA of the plastin mRNA. By the use of a degenerate oligonucleotide probe derived from an internal protein sequence of plastin directly isolated from analytical 2-D electrophoretic gels, we have identified two different, but highly related, cDNA clones of plastin mRNA. Our main conclusions are the following: (1) there exist at least two isoforms of plastin, l-plastin and t-plastin; (ii) the expression of 1-plastin and t-plastin is regulated in a tissue-specific manner; and (iii) l-plastin is a marker protein for transformed cells of fibroblasts and some cells of epithelial or endothelial origin.

\section{MATERIALS AND METHODS}

Methods for growing cells for the preparation of cellular RNA, genomic DNA, and protein extracts and the proce- 
dure for 2-D gel electrophoresis have been described in detail previously $(22,23,25)$. Silver staining of proteins in a gel was done by the procedure of Merril et al. (30).

Protein sequencing. Protein sequencing methods have been described previously $(1-3,17)$. In brief, cellular proteins were separated by 2-D gel electrophoresis and transferred to nitrocellulose paper, each protein spot of interest was cut out and digested by trypsin, and the resulting peptides were separated by narrow-bore, reverse-phase high-pressure liquid chromatography and sequenced in a gas phase sequenator.

Screening of cDNA library. A $\lambda$ gt10 cDNA library constructed from HuT-14 poly(A) ${ }^{+}$RNA has been described previously (25). A probe containing eightfold degenerate 20-mer oligodeoxynucleotides (see Results) was end labeled with ${ }^{32} \mathrm{P}$ and used to screen this library. The screening procedures were essentially the same as previously described (25), except the hybridization temperature was lowered to $37^{\circ} \mathrm{C}$ and washing was less stringent with a higher salt concentration $(4 \times \mathrm{SSC}[1 \times \mathrm{SSC}$ is $0.15 \mathrm{M} \mathrm{NaCl}$ plus 0.015 $\mathrm{M}$ sodium citrate, $\mathrm{pH}$ 7]).

Northern (RNA) analysis. Total cellular RNA was prepared by the guanidine hydrochloride method as described previously (15). Approximately $5 \mu \mathrm{g}$ of each RNA was size fractionated in a $1 \%$ agarose gel containing $50 \mathrm{mM}$ MOPS (morpholinepropanesulfonic acid) buffer $(\mathrm{pH} 7), 1 \mathrm{mM}$ EDTA, and 2.2 M formaldehyde, transferred to nitrocellulose paper, and hybridized to ${ }^{32} \mathrm{P}$-labeled probes. Hybridization proceeded overnight at $65^{\circ} \mathrm{C}$ in a solution containing $4 \times$ SSC, $5 \times$ Denhardt solution (8), $50 \mathrm{mM}$ phosphate buffer $(\mathrm{pH}$ 7), $10 \%(\mathrm{wt} / \mathrm{vol})$ dextran sulfate, and $2 \times 10^{6} \mathrm{cpm}$ of probe per $\mathrm{ml}$. Washing was carried out twice in $1 \times \mathrm{SSC}-0.1 \%$ (wt/ vol) sodium dodecyl sulfate at room temperature for $5 \mathrm{~min}$ each and twice in $0.5 \times \mathrm{SSC}-0.1 \%$ sodium dodecyl sulfate at $65^{\circ} \mathrm{C}$ for $30 \mathrm{~min}$ each.

Genomic analysis. Genomic DNA was prepared as described by Maniatis et al. $(26,27)$. Approximately $10 \mu \mathrm{g}$ of each DNA was digested with HindIII to completion, electrophoresed on a $\mathbf{0 . 7 \%}$ agarose gel, and transferred to nitrocellulose paper by the method described by Southern (35). Hybridization and washing of the nitrocellulose paper were the same as described above.

DNA sequencing. DNA was cloned into M13mp9 (31). Progressive deletion clones were prepared by the method described by Dale et al. (7) and sequenced by the method described by Sanger et al. (34). Sequence information was managed by Bionet of Intelligenetics Inc., Palo Alto, Calif.

In vitro message selection-translation. To confirm the identity of a cDNA, in vitro message selection-translation was used. We have described this methodology in detail previously (25). In brief, cDNA was bound to nitrocellulose paper and hybridized with poly $(\mathrm{A})^{+}$RNA, hybridized RNA was recovered and translated in a rabbit reticulocyte system, and the translational product was separated by 2-D gel electrophoresis and visualized by autoradiography.

\section{RESULTS}

Evidence for two isoforms. We initially attempted a differential hybridization approach, using two probes derived from mRNAs of diploid ("plastin-negative") KD fibroblast cells and transformed ("plastin-positive") HuT-14 fibroblast cells, to screen cDNA libraries constructed from poly $(\mathrm{A})^{+}$ RNAs of human HuT-14 fibrosarcoma cells (23) and human T-lymphocyte cells (purchased from Clontech, Inc.). Despite repeated screening of these libraries and analysis of potential clones, we were unable to find a clone that would hybridize to only RNAs of "plastin-positive" cells.

As an alternative approach, we applied two new isolation techniques which we had developed for protein microsequencing (1-3) that enabled us to obtain sequence information for proteins purified from 2-D gels. For N-terminal sequence analysis, proteins were electroblotted from analytical 2-D gels onto chemically modified glass fiber filter paper and detected by fluorescent staining. Plastin spots were cut out and inserted into the sequenator cartridge for direct sequence analysis $(1,3)$. In repeated attempts we were unable to obtain an $\mathrm{N}$-terminal sequence from $\mathrm{T}$-lymphocyte plastin, although proteins expressed at comparable levels and simultaneously isolated from the same 2-D gels could readily be sequenced (1). This suggested that plastin was blocked at the amino-terminal end. Using our newly developed procedure (2), we then attempted to obtain internal protein sequence information of plastin. Proteins in a total cell lysate of CEM lymphoblastoid cells were separated by 2-D gel electrophoresis and electroblotted onto nitrocellulose. Plastin-containing spots were excised and enzymatically cleaved on the nitrocellulose matrix (2). The resulting peptides were separated by narrow-bore, reverse-phase high-pressure liquid chromatography, and individual peptide fragments were sequenced in a modified Caltech gas phase sequenator (17). Four peptide sequences that were unambiguously identified are listed in Table 1 , footnote $a$.

We synthesized a degenerate oligonucleotide 20 -mer corresponding to one of the four oligopeptides (Table 1) and used it to screen a $\lambda \mathrm{gt} 10$ cDNA library of transformed (HuT-14) human fibroblasts (25). From approximately 10,000 recombinants the probe selected a single clone, P4. The cDNA insert of P4 was 4.3 kilobases $(\mathrm{kb})$ in length. (We later concluded that this large cDNA was composed of two unrelated cDNA fragments of 1.0 and $3.3 \mathrm{~kb}$ that were ligated during the construction of the library [data not shown].) A 2-kb HindIII fragment within the 3.3-kb cDNA insert of P4 hybridized to an mRNA of $3.4 \mathrm{~kb}$ (Fig. 1A) that was more abundant in HuT-14 (lane 3) than in normal KD (lane 2) fibroblasts and not detectable in CEM T lymphocytes (lane 1). This result was disappointing since plastin mRNA should be more abundant in CEM than in HuT-14 and absent in diploid fibroblasts (13). However, when we sequenced the cDNA, we found four of the oligopeptide sequences that we had unambiguously identified by direct amino acid sequence determination (Table 1 and Fig. 2). The four sequences, peptides $1,2,6$, and 7, starting at amino acid residues $85,132,458$, and 489 , respectively, could be unambiguously identified. The other four sequences (peptides 3,4 , 5 , and 8 ) were deduced from mixed sequences by using the completed cDNA sequence.

There were, however, six differences between the protein sequence (residues $85,94,132,459,491$, and 496) derived from the lymphocyte plastin protein sequence and the reverse-translated cDNA sequence of the cDNA isolated from transformed fibroblasts (Fig. 2). These differences suggested that a different, but closely related, cDNA had been cloned. To identify the protein translation product of the cloned P4 cDNA, we used the entire 4.3-kb cDNA insert to select for mRNAs by hybridization with poly (A) ${ }^{+}$RNA of HuT-14 and subsequently translated the selected mRNAs in vitro. We found that the most prominent translation products were two proteins ( $t$-plastins) migrating to more basic isoelectric points than the polypeptide recognized as plastin in the 2-D gel (Fig. 3F and G). These two proteins were synthesized abundantly in both normal and transformed human fibro- 
TABLE 1. Synthesis of a degenerate oligonucleotide probe for plastin ${ }^{a . b}$

\begin{tabular}{|c|c|c|c|}
\hline $\begin{array}{l}\text { Amino acid } \\
\text { position }\end{array}$ & $\begin{array}{l}\text { Oligopeptide } \\
\text { sequence }\end{array}$ & $\begin{array}{l}\text { Oligonucleotide } \\
\text { probe (antisense) }\end{array}$ & $\begin{array}{l}\text { Corresponding l-plastin } \\
\text { nucleotide sequence } \\
\text { (sense) }\end{array}$ \\
\hline 1 & Val & $\begin{array}{l}\text { C } \\
\text { A } \\
\text { CG }\end{array}$ & $\begin{array}{l}\mathrm{G} \\
\mathrm{T} \\
\mathrm{C}\end{array}$ \\
\hline 2 & Asn & $\begin{array}{l}\text { T } \\
\text { T } \\
\text { AG }\end{array}$ & $\begin{array}{l}\text { A } \\
\text { A } \\
\text { T }\end{array}$ \\
\hline 3 & Asp & $\begin{array}{l}\mathrm{C} \\
\mathrm{T} \\
\mathrm{AG}\end{array}$ & $\begin{array}{l}\text { G } \\
\text { A } \\
\text { T }\end{array}$ \\
\hline 4 & Asp & $\begin{array}{l}\mathrm{C} \\
\mathrm{T} \\
\mathrm{AG}\end{array}$ & $\begin{array}{l}\text { G } \\
\text { A } \\
\text { C }\end{array}$ \\
\hline 5 & Ile & $\begin{array}{l}\text { T } \\
\text { A } \\
\text { I }\end{array}$ & $\begin{array}{l}\mathrm{A} \\
\mathrm{T} \\
\mathrm{T}\end{array}$ \\
\hline 6 & Ile & $\begin{array}{l}\text { T } \\
\text { A } \\
\text { I }\end{array}$ & $\begin{array}{l}\mathrm{A} \\
\mathrm{T} \\
\mathrm{T}\end{array}$ \\
\hline 7 & Val & $\begin{array}{l}\text { C } \\
\text { A }\end{array}$ & $\begin{array}{l}G \\
T\end{array}$ \\
\hline
\end{tabular}

${ }^{a}$ The four unambiguous plastin peptide sequences identified were the following: (i) ...Glu-Val-Ile-Pro-Met-Asn-Pro-Asn-Ser/or Thr-Asn-Asp-blankPhe-blank-Ala-Val...; (ii) ...Thr-Ile-Gln-Glu-Asn-Leu-Asn-Leu-Ala-Leu-AsnSer-Ala-Ser-blank-Ile-Gly...; (iii) ...Val-Asn-Asp-Asp-Ile-Ile-Val-Asn-TyrVal-Asn-Glu...; (iv) ...Ile-Ser-Thr-Ser-Leu-blank-Val-Leu-Asp-Leu-Ile-Asp.... ${ }^{b}$ An eightfold degenerate 20 -nucleotide probe was designed from the l-plastin peptide 3 sequence that exhibited a relatively low degeneracy. This oligonucleotide was synthesized by using an ABI solid-phase synthesizer. We preferred to use a relatively short oligonucleotide probe with low degeneracy. To further minimize degeneracy, we made use of preferred codon usage for valine and the weak base pair-stabilizing characteristics of inosine (I) in the isoleucine codon (32).

c 3' End, ....

blasts (Fig. 3B and C), but were undetectable in leukocytes (Fig. 3A and E). As these two proteins were apparently similar to plastin, we decided to use the 2-kb HindIII fragment of P4 cDNA as a probe to rescreen the HuT-14 cDNA library in the hope of finding related cDNAs.

Several clones were identified by this rescreening. One of them, P107, had the largest insert cDNA (3.7 kb) and was chosen for further examination. In Northern analysis (Fig. 1B), P107 hybridized to an mRNA of $3.7 \mathrm{~kb}$ that was more abundant in CEM lymphocytes (lane 1), less abundant in transformed HuT-14 fibroblasts (lane 3), and not detectable in untransformed KD fibroblasts (lane 2). This was the predicted pattern for 1-plastin mRNA expression in these three cell types (13). Translation of HuT-14 mRNAs selected by this clone yielded a single polypeptide species that appeared to be identical to l-plastin in a 2-D gel (Fig. 3H). We established that this in vitro-synthesized polypeptide was electrophoretically identical to l-plastin by mixing the in vitro translation sample in Fig. $3 \mathrm{H}$ with labeled unfractionated HuT-12 cellular proteins (23) shown in Fig. 3J. The in vitro-translated l-plastin, which was in excess of the endogenous HuT-12 l-plastin, was superimposed upon the endogenous 1-plastin after 2-D gel electrophoresis (Fig. 3K). We therefore concluded that P107 is the true cDNA clone of

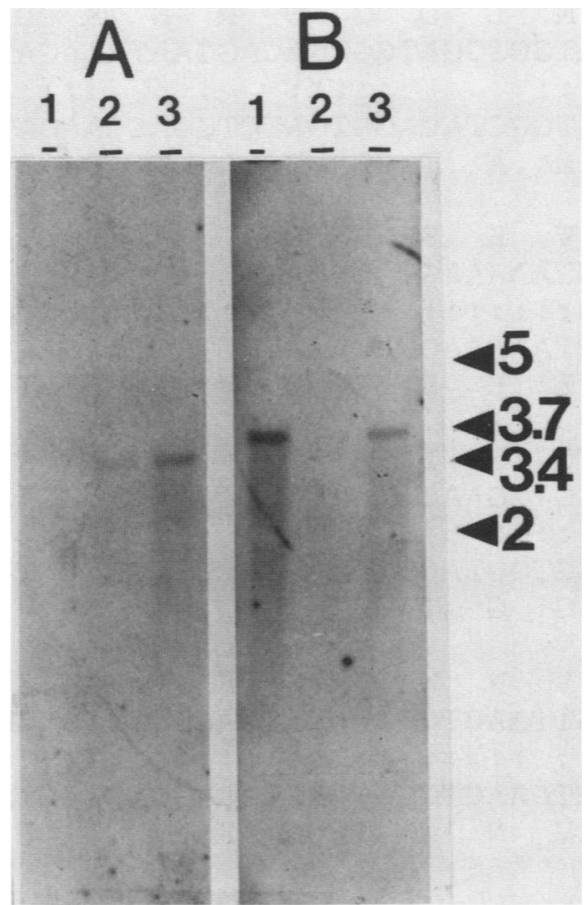

FIG. 1. Northern analysis for cDNA clones. Two identical Northern blots (A and B) were hybridized with ${ }^{32} \mathrm{P}$-labeled cDNAs of P4 (A) and P107 (B), respectively. Each blot contains cellular RNAs of CEM (lane 1), KD (lane 2), and HuT-14 (lane 3). Size markers on the right are $28 \mathrm{~S}$ and $18 \mathrm{~S}$ rRNAs $(5$ and $2 \mathrm{~kb}$, respectively.)

1-plastin, whereas P4 cDNA encoded separate polypeptide isoforms, $t$-plastins, which closely related to l-plastin.

DNA sequencing of P107 cDNA revealed a coding sequence closely related to that of the initially characterized P4 clone (Fig. 2). The P107 cDNA sequence contained the amino acid residues determined by protein sequence analysis of plastin isolated from CEM lymphocytes in the positions where discrepancies had existed between the protein sequence and the P4 cDNA sequence. Each coding sequence encoded a polypeptide of 570 amino acids with molecular weight of 64,000 . This value is slightly different from our observed $M_{\mathrm{r}}$ value of l-plastin and the two t-plastin polypeptides $\left(M_{\mathrm{r}}, 68,000\right)$ in a 2-D gel $(13,23)$, but is consistent with the value for l-plastin observed by others $(18,29)$. Our predicted amino acid composition obtained for plastin by computerized microdensitometry was consistent with the amino acid composition determined from these DNA sequences (13).

The existence of two closely related plastin isoforms, 1-plastin of leukocytes and the t-plastins of normal fibroblasts, explains why we were unable to identify plastin cDNA clones through differential hybridization, for the plastin-negative fibroblast probe contained t-plastin sequences that would hybridize to any l-plastin clones. That 1-plastin is expressed in leukocytes and in transformed fibroblasts (HuT-14) but not in normal fibroblasts is confirmed because the oligopeptide sequences were derived from l-plastin of lymphocytes and the 1-plastin cDNA clone was isolated from transformed HuT-14 fibroblasts. The t-plastin isoforms, on the other hand, are expressed in both normal and transformed fibroblasts, but not in leukocytes.

Differential expression of plastin isoforms in human cell transformation. We surveyed a panel of cultured human cell 


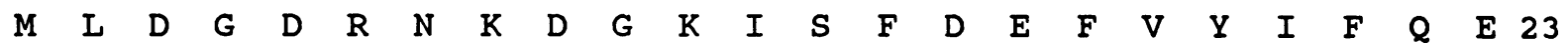 p4-ATGCTGGATGGTGACAGGAATAAAGATGGGAAAATAAGTTTTGACGAATTTGTTTATATTTTTCAAGAG

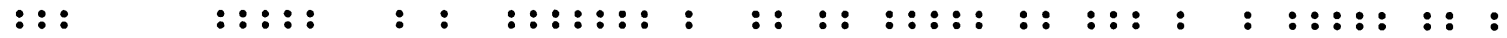 p107-ATGGCTACAGGTGATCTGGACCAAGATGGAAGGATCAGCTTTGATGAGTTTATCAAGATTTTCCATGGC $\begin{array}{lllllllllllllllllllllll}M & A & T & G & D & L & D & Q & D & G & R & I & S & F & D & E & F & I & K & I & F & H & G\end{array}$ $\begin{array}{llllllllllllllllllllllllllll}V & K & S & S & D & I & A & K & T & F & R & K & A & I & N & R & K & E & G & I & C & A & L & 46\end{array}$ GTAAAAAGTAGTGATATTGCCAAGACCTTCCGCAAAGCAATCAACAGGAAAGAAGGTATTTGTGCTCTG : : : : : : : : : : : : : : : : : : : : : : : : : : : : : : : : : : : : : : : : : :::: : : : ::::::: : CTAAAAAGCACAGATGTTGCCAAGACCTTTAGAAAAGCAATCAATAAGAAGGAAGGGATTTGTGCAATC $\begin{array}{lllllllllllllllllllllll}\mathrm{L} & \mathrm{K} & \mathrm{S} & \mathrm{T} & \mathrm{D} & \mathrm{V} & \mathrm{A} & \mathrm{K} & \mathrm{T} & \mathrm{F} & \mathrm{R} & \mathrm{K} & \mathrm{A} & \mathrm{I} & \mathrm{N} & \mathrm{K} & \mathrm{K} & \mathrm{E} & \mathrm{G} & \mathrm{I} & \mathrm{C} & \mathrm{A} & \mathrm{I}\end{array}$ $\begin{array}{llllllllllllllllllllllll}G & G & T & S & E & \text { L } & S & S & E & G & T & Q & H & S & Y & S & E & E & E & K & Y & A & F & 69\end{array}$ GGTGGAACTTCAGAGTTGTCCAGCGAAGGAACACAGCATTCTTACTCAGAGGAAGAAAAATATGCTTTT : : : : : : : : : : : : : : : : : : : : : : : : : : : : : : : : : : : : : : : : : : : : : : : : : : : : : : GGTGGTACTTCAGAGCAGTCTAGCGTTGGCACCCAACACTCCTATTCAGAGGAAGAAAAGTATGCCTTT $\begin{array}{lllllllllllllllllllllll}G & G & T & S & E & Q & S & S & V & G & T & Q & H & S & Y & S & E & E & E & K & Y & A & F\end{array}$ $\begin{array}{llllllllllllllllllllllll}\mathrm{V} & \mathrm{N} & \mathrm{W} & \mathrm{I} & \mathrm{N} & \mathrm{K} & \mathrm{A} & \mathrm{L} & \mathrm{E} & \mathrm{N} & \mathrm{D} & \mathrm{P} & \mathrm{D} & \mathrm{C} & \mathrm{R} & \mathrm{H} & \mathrm{V} & \mathrm{I} & \mathrm{P} & \mathrm{M} & \mathrm{N} & \mathrm{P} & \mathrm{N} & 92\end{array}$ GTTAACTGGATAAACAAAGCTTTGGAAAATGATCCTGATTGTAGACATGTTATACCAATGAACCCTAAC : : : : : : : : : : : : : : : : : : : : : : : : : : : : : : : : : : : : : : : : : : : : : : : : : : : : : : : : : : : GTCAACTGGATAAACAAAGCCCTGGAAAATGATCCTGATTGTCGGCATGTCATCCCAATGAACCCAAAC $\begin{array}{lllllllllllllllllllllll}\mathrm{V} & \mathrm{N} & \mathrm{W} & \mathrm{I} & \mathrm{N} & \mathrm{K} & \mathrm{A} & \mathrm{L} & \mathrm{E} & \mathrm{N} & \mathrm{D} & \mathrm{P} & \mathrm{D} & \mathrm{C} & \mathrm{R} & \mathrm{H} & \mathrm{V} & \mathrm{I} & \mathrm{P} & \mathrm{M} & \mathrm{N} & \mathrm{P} & \mathrm{N}\end{array}$ peptide $\# I \rightarrow E$ V $\quad I \quad P \quad M \quad N \quad P \quad N$ \\ $\begin{array}{lllllllllllllllllllllllll}T & D & D & \text { L } & F & K & A & V & G & D & G & I & V & I & C & K & M & I & N & L & S & V & P & 115\end{array}$ ACCGATGACCTGTTCAAAGCTGTTGGTGATGGAATTGTGCTTTGTAAAATGATTAACCTTTCAGTTCCT : : : : : : : : : : : : : : : : : : : : : : : : : : : : : : : : : : : : : : : : : : : : : : : : : : ACGAATGATCTCTTTAATGCTGTTGGAGATGGCATTGTCCTTTGTAAAATGATCAACCTGTCAGTGCCA \\ $\begin{array}{lllllllllllllllllllllll}T & N & D & L & F & N & A & V & G & D & G & I & V & I & C & K & M & I & N & L & S & V & P\end{array}$ $S / T N D-F-A V$ \\ $\begin{array}{lllllllllllllllllllllllll}D & T & I & D & E & R & A & I & N & K & K & K & L & T & P & F & I & I & Q & E & N & L & N & 138\end{array}$ GATACCATTGATGAAAGAGCAATCAACAAGAAGAAACTTACACCCTTCATCATTCAGGAAAACTTGAAC : : : : : : : : : : : : : : : : : : : : : : : : : : : : : : : : : : : : : : : : : : : : : : : : : : : : : : : GACACAATTGATGAAAGAACAATCAACAAAAAGAAGCTAACCCCTTTCACCATTCAGGAAAATCTGAAC $\begin{array}{llllllllllllllllllllllllll}\mathrm{D} & \mathrm{T} & \mathrm{I} & \mathrm{D} & \mathrm{E} & \mathrm{R} & \mathrm{T} & \mathrm{I} & \mathrm{N} & \mathrm{K} & \mathrm{K} & \mathrm{K} & \mathrm{L} & \mathrm{T} & \mathrm{P} & \mathrm{F} & \mathrm{T} & \mathrm{I} & \mathrm{Q} & \mathrm{E} & \mathrm{N} & \mathrm{L} & \mathrm{N}\end{array}$ peptide $\# 2 \rightarrow T$ I $Q$ E $N$ I $N$ \\ $\begin{array}{llllllllllllllllllllllll}I & A & L & N & S & A & S & A & I & G & C & H & V & V & N & I & G & A & E & D & L & R & A & 161\end{array}$ TTGGCACTGAACTCTGCTTCTGCCATTGGGTGTCATGTTGTGAACATTGGTGCAGAAGATTTGAGGGCT

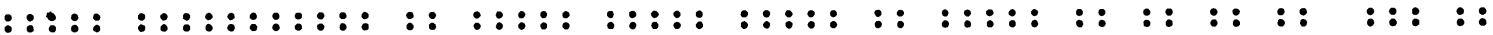 TTGGCTCTGAACTCTGCCTCAGCCATCGGGTGCCATGTGGTCAACATAGGGGCTGAGGACCTGAAGGAG \\ $\begin{array}{llllllllllllllllllllllll}\mathrm{L} & \mathrm{A} & \mathrm{L} & \mathrm{N} & \mathrm{S} & \mathrm{A} & \mathrm{S} & \mathrm{A} & \mathrm{I} & \mathrm{G} & \mathrm{C} & \mathrm{H} & \mathrm{V} & \mathrm{V} & \mathrm{N} & \mathrm{I} & \mathrm{G} & \mathrm{A} & \mathrm{E} & \mathrm{D} & \mathrm{L} & \mathrm{K} & \mathrm{E}\end{array}$

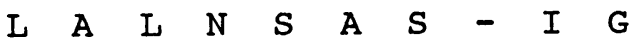

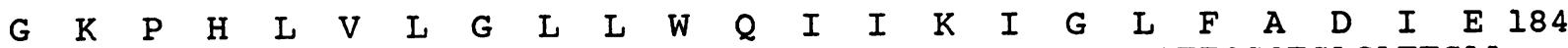 GGGAAACCTCATCTGGTTTTGGGACTGCTTTGGCAGATCATTAAGATCGGTTTGTTCGCTGACATTGAA

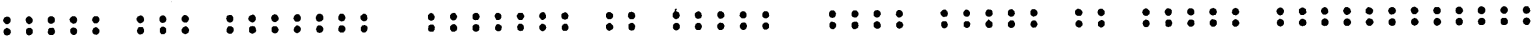 GGGAAGCCTTATCTGGTCCTGGGACTTCTGTGGCAAGTCATCAAGATTGGGTTGTTTGCTGACATTGAA

$\begin{array}{lllllllllllllllllllllll}G & K & P & Y & I & V & L & G & \text { L } & \text { L } & \text { W } & Q & V & I & K & I & G & \text { L } & F & A & D & I & E\end{array}$

FIG. 2. Coding sequences and deduced amino acid sequences of P4 cDNA (top) and P107 cDNA (bottom). Identical nucleotides between the two sequences are indicated by double dots. The eight oligopeptide sequences determined by microsequencing of plastin polypeptide are indicated.

strains by Northern analysis for 1-plastin (Fig. 4A) and t-plastin (Fig. 4B) mRNA. l-Plastin mRNA and protein were not detected in the diploid human fibroblast strains $\mathrm{KD}$ and R17 (Fig. 4A, lanes 1 and 2; example shown in Fig. 3B), but both strains exhibited t-plastin mRNA (Fig. 4B, lanes 1 and 2) and protein (example shown in Fig. 3B). We examined more than 50 additional diploid human fibroblast strains derived from embryonic lung, skin, foreskin, and gingiva from normal individuals and from patients with various genetic diseases such as Huntington's disease, Bloom's syndrome, ataxia telangiectasia, and retinoblastoma. Without exception all diploid fibroblast strains exhibited expres- 
$\begin{array}{lllllllllllllllllllllllll}L & S & R & N & E & A & L & A & A & L & L & R & D & G & E & T & L & E & E & L & M & K & \text { L } & 207\end{array}$ TTAAGCAGGAATGAAGCCTTGGCTGCTTTACTCCGAGATGGTGAGACTTTGGAGGAACTTATGAAATTG

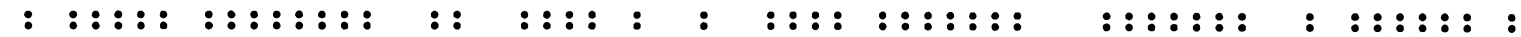
CTCAGCAGAAATGAAGCTCTGATTGCTCTTTTGAGAGAAGGTGAGAGCCTGGAGGATTTGATGAAACTC $\begin{array}{lllllllllllllllllllllll}I & S & R & N & E & A & L & I & A & L & L & R & E & G & E & S & L & E & D & L & M & K & L\end{array}$ L

$\begin{array}{lllllllllllllllllllllllll}S & P & E & E & L & L & L & R & W & A & N & F & H & L & E & N & S & G & W & Q & K & I & N & 230\end{array}$ TCTCCAGAAGAGCTTCTGCTTAGATGGGCAAACTTTCATTTGGAAAACTCGGGCTGGCAAAAAATTAAC

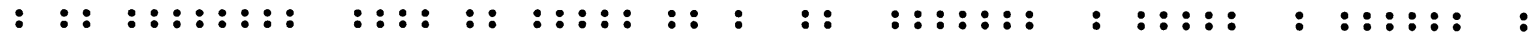
TCCCCTGAAGAGCTCTTGCTGAGGTGGGCTAATTACCACCTGGAAAATGCAGGCTGCAACAAAATTGGC $\begin{array}{llllllllllllllllllllllll}S & P & E & E & L & L & L & R & W & A & N & Y & H & L & E & N & A & G & C & N & K & I & G\end{array}$

$\begin{array}{lllllllllllllllllllllllll}N & F & S & A & D & I & K & D & S & K & A & Y & F & H & L & I & N & Q & I & A & P & K & G & 253\end{array}$ AACTTTAGTGCTGACATCAAGGATTCCAAAGCCTATTTCCATCTTCTCAATCAAATCGCACCAAAAGGA

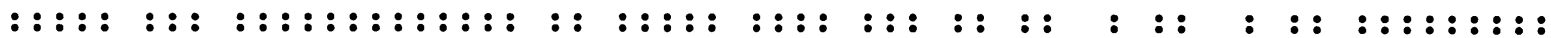
AACTTCAGTACTGACATCAAGGACTCAAAAGCTTATTACCACCTGCTTGAGCAGGTGGCTCCAAAAGGA $\begin{array}{llllllllllllllllllllllll}N & F & S & T & D & I & K & D & S & K & A & Y & Y & H & L & L & E & Q & V & A & P & K & G\end{array}$ $\begin{array}{lllllllllllllllllllllllll}Q & K & E & G & E & P & R & I & D & I & N & M & S & G & F & N & E & T & D & D & L & K & R & 276\end{array}$ CAAAAGGAAGGTGAACCACGGATAGATATTAACATGTCAGGTTTCAATGAAACAGATGATTTGAAGAGA

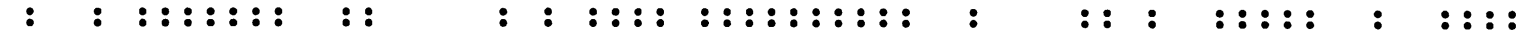
GATGAAGAAGGTGTTCCTGCTGTTGTTATTGACATGTCAGGACTGCGGGAGAAGGATGACATCCAGAGG $\begin{array}{llllllllllllllllllllllll}D & E & E & G & V & P & A & V & V & I & D & M & S & G & I & R & E & K & D & D & I & Q & R\end{array}$ $\begin{array}{lllllllllllllllllllllllll}A & E & S & M & L & Q & Q & A & D & K & L & G & C & R & Q & F & V & T & P & A & D & V & V & 299\end{array}$ GCTGAGAGTATGCTTCAACAAGCAGATAAATTAGGTTGCAGACAGTTTGTTACCCCTGCTGATGTTGTC

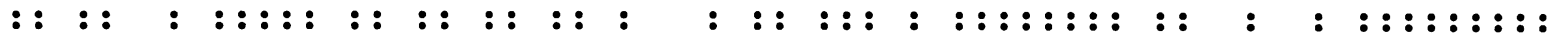
GCAGAATGCATGCTGCAGCAGGCGGAGAGGCTGGGCTGCCGGCAGTTTGTCACAGCCACAGATGTTGTC $\begin{array}{lllllllllllllllllllllll}A & E & C & M & L & Q & Q & A & E & R & L & G & C & R & Q & F & V & T & A & T & D & V & V\end{array}$ $\begin{array}{lllllllllllllllllllllllll}S & G & N & P & K & L & N & L & A & F & V & A & N & L & F & N & K & Y & P & A & L & T & K & 322\end{array}$ AGTGGAAACCCCAAACTCAACTTAGCTTTCGTGGCTAACCTGTTTAATAAATACCCAGCACTAACTAAG

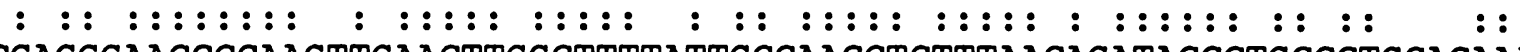
CGAGGGAACCCCAAGTTGAACTTGGCTTTTATTGCCAACCTCTTTAACAGATACCCTGCCCTGCACAAA $\begin{array}{lllllllllllllllllllllllll}R & G & N & \mathbf{P} & K & \text { L } & N & \text { L } & A & F & I & A & N & I & F & N & R & Y & P & A & I & H & K\end{array}$ $\begin{array}{lllllllllllllllllllllllll}P & E & N & Q & D & I & D & W & T & \text { L } & \text { L } & E & G & E & T & R & E & E & R & T & F & R & N & 345\end{array}$ CCAGAGAACCAGGATATTGACTGGACTCTATTAGAAGGAGAAACTCGTGAAGAAAGAACCTTCCGTAAC : : : : : : : : : : : : : : : : : : : : : : : : : : : : : : : : : : :: : $:$ : : : : : : : : CCAGAGAACCAGGACATTGACTGGGGGGCTCTTGAAGGTGAGACGAGAGAAGAGCGGACATTTAGGAAC $\begin{array}{lllllllllllllllllllllll}P & E & N & Q & D & I & D & W & G & A & L & E & G & E & T & R & E & E & R & T & F & R & N\end{array}$

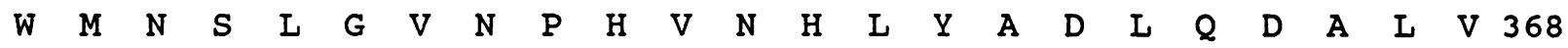
TGGATGAACTCTCTTGGTGTCAATCCTCACGTAAACCATCTCTATGCTGACCTGCAAGATGCCCTGGTA : : : : : : : : : : : : : : : : : : : : : : : : : : : : : : : : : : : : : : : : : : : : : : : : : : : TGGATGAACTCCCTGGGTGTTAACCCTCGAGTCAATCATTTGTACAGTGACTTATCAGATGCCCTGGTC $\begin{array}{llllllllllllllllllllllll}W & M & N & S & L & G & V & N & P & R & V & N & H & L & Y & S & D & I & S & D & A & I & V\end{array}$ peptide \#4 $\rightarrow \mathrm{V}-\mathrm{N} Y$ - D L

$\begin{array}{llllllllllllllllllllllll}I & L & Q & L & Y & E & R & I & K & V & P & V & D & W & S & K & V & N & K & P & P & Y & P & 391\end{array}$ ATCTTACAGTTATATGAACGAATTAAAGTTCCTGTTGACTGGAGTAAGGTTAATAAACCTCCATACCCG : : : : : : : : : : : : : : : : : : : : : : : : : : : : : : : : : : : : : : : : : : : : : : : : : : : : : : : ATCTTCCAGCTCTATGAAAAGATCAAAGTTCCTGTTGACTGGAACAGAGTAAACAAACCGCCATACCCC $\begin{array}{lllllllllllllllllllllll}I & F & Q & L & Y & E & K & I & K & V & P & V & D & W & N & R & V & N & K & P & P & Y & P\end{array}$ FIG. 2-Continued

sion of $\mathrm{t}$-plastin in 2-D protein profiles, but not l-plastin. The two transformed fibroblast strains, HuT-12 and HuT-14, derived after mutagenesis of the KD cell culture (23), exhibited increasing levels of 1-plastin mRNAs (Fig. 4, lanes 3 and 4 , respectively), consistent with our previous observations with 2-D protein gel analysis for these two cell lines (23). The tumorigenic strain HuT-14 expressed more l-plastin mRNA and protein than did the three nontumorigenic $\mathrm{HuT}$ strains (HuT-11, -12, and -13) (Fig. 3C and D; Fig. 4A, lanes 3 and 4; references 20 and 23). HuT-14T, an even more tumorige- 
$\begin{array}{lllllllllllllllllllllllll}K & \text { L } & G & A & N & M & K & K & \text { L } & \text { E } & \text { N } & \text { C } & \text { N } & \text { Y } & \text { A } & \text { V } & \text { E } & \text { L } & G & \text { K } & \text { H } & \text { P } & \text { A } & 414\end{array}$ AAACTGGGAGCCAACATGAAAAAGCTAGAAAACTGCAACTATGCTGTTGAATTAGGGAAGCATCCTGCT : : : : : : : : : : : : : : : : : : : : : : : : : : : : : : : : : : : : : : : : : : : : : : : : : : : : : : AAACTGGGAGGCAATATGAAGAAGCTTGAGAATTGTAACTACGCGGTAGAATTGGGGAAGAATCAAGCG $\begin{array}{lllllllllllllllllllllll}K & \text { L } & G & G & N & M & K & K & \text { L } & \text { E } & \text { N } & \text { C } & \text { N } & \text { Y } & \text { A } & \text { V } & \text { E } & \text { L } & \text { G } & \text { K } & \text { N } & \mathbf{Q} & A\end{array}$

$\begin{array}{lllllllllllllllllllllllll}K & F & S & \text { L } & \text { V } & G & \text { I } & G & G & Q & \text { D } & \text { L } & \text { N } & \text { D } & G & \text { N } & \text { Q } & \text { T } & \text { L } & \text { T } & \text { L } & \text { A } & \text { L } & 437\end{array}$ AAATTCTCCCTGGTTGGCATTGGAGGGCAAGACCTGAATGATGGGAACCAAACCCTGACTTTAGCTTTA : : : : : : : : : : : : : : : : : : : : : : : : : : : : : : : : : : : : : : : : : : : : : : : : : : : : AAGTTCTCCCTGGTTGGCATCGGTGGACAAGATCTCAATGAAGGAAACCGCACTCTCACACTGGCCTTG

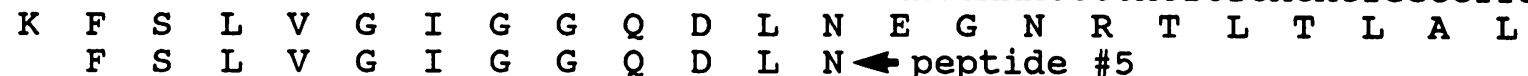
$\begin{array}{llllllllllllllllllllllll}V & W & Q & I & M & R & R & Y & T & L & N & V & L & E & D & \text { L } & G & D & G & Q & K & A & N & 460\end{array}$ GTCTGGCAGCTGATGAGAAGATATACCCTCAATGTCCTGGAAGATCTTGGAGATGGTCAGAAAGCCAAT

: : : : : : : : : : : : : : : : : : : : : : : : : : : : : : : : : : : : : : : : : : : : : : : : : : : : : : ATTTGGCAGCTAATGAGAAGGTATACACTGAATATCCTCGAAGAAATTGGTGGTGGCCAGAAGGTCAAT

$\begin{array}{lllllllllllllllllllllll}I & W & Q & L & M & R & R & Y & T & L & N & I & L & E & E & I & G & G & G & Q & K & V & N \\ \text { peptide } & \# 6 & V & N\end{array}$

$\begin{array}{llllllllllllllllllllllll}D & D & I & I & V & N & W & V & N & R & T & I & S & E & A & G & K & S & T & S & I & Q & S & 483\end{array}$ GACGACATCATTGTGAACTGGGTGAACAGAACGTTGAGTGAAGCTGGAAAATCAACTTCCATTCAGAGT : : : : : : : : : : : : : : : : : : : : : : : : : : : : : : : : : : : : : : : : $:$ : : : : : GATGACATTATTGTCAACTGGGTGAATGAAACATTGAGGGAAGCAGAGAAAAGTTCATCCATCTCTAGT

$\begin{array}{lllllllllllllllllllllll}D & D & I & I & V & N & W & V & N & E & T & I & R & E & A & E & K & S & S & S & I & S & S \\ D & D & I & I & V & N & W & V & N & E & & & & & & & & & & & & \end{array}$ $\begin{array}{llllllllllllllllllllllll}F & K & D & K & T & I & S & S & S & L & A & V & V & D & I & I & D & A & I & Q & P & G & C & 506\end{array}$ TTTAAGGACAAGACGATCAGCTCCAGTTTGGCAGTTGTGGATTTAATTGATGCCATCCAGCCAGGCTGT : : : : : : : : : : : : : : : : : : : : : : : : : : : : : : : : : : : : : : : : : : : : : : : : : TTCAAGGACCCGAAGATTAGTACAAGTCTGCCTGTTCTGGACCTCATCGATGCCATCCAACCAGGTTCC

$\begin{array}{lllllllllllllllllllllll}\mathbf{F} & \mathrm{K} & \mathrm{D} & \mathrm{P} & \mathrm{K} & \mathrm{I} & \mathrm{S} & \mathrm{T} & \mathrm{S} & \mathrm{L} & \mathrm{P} & \mathrm{V} & \mathrm{L} & \mathrm{D} & \mathrm{I} & \mathrm{I} & \mathrm{D} & \mathrm{A} & \mathrm{I} & \boldsymbol{Q} & \mathrm{P} & \mathrm{G} & \mathbf{S}\end{array}$ peptide $\# 7 \rightarrow I$ S T S I - V I D I I D

$\begin{array}{lllllllllllllllllllllllll}I & N & Y & D & \text { L } & \text { V } & \text { K } & \text { S } & G & \text { N } & \text { L } & \text { T } & \text { E } & \text { D } & \text { D } & \text { K } & \text { H } & \text { N } & \text { N } & A & \text { K } & \text { Y } & \text { A } & 529\end{array}$ ATAAACTATGACCTTGTGAAGAGTGGCAATCTAACAGAAGATGACAAGCACAATAATGCCAAGTATGCA : : : : : : : : : : : : : : : : : : : : : : : : : : : : : : : : : : : : : : : : : : : : : : : : : : : : ATTAACTATGACCTTCTGAAGACAGAAAATCTGAATGATGATGAGAAACTCAACAATGCAAAATATGCC $\begin{array}{lllllllllllllllllllllll}I & N & Y & D & L & I & K & T & E & N & L & N & D & D & E & K & I & N & N & A & K & Y & A\end{array}$ $\begin{array}{lllllllllllllllllllllllll}V & S & M & A & R & R & I & G & A & R & V & Y & A & L & P & E & D & I & V & E & V & K & P & 552\end{array}$ GTGTCAATGGCTAGAAGAATCGGAGCCAGAGTGTATGCTCTCCCTGAAGACCTTGTGGAAGTAAAGCCC : : : : : : : : : : : : : : : : : : : : : : : : : : : : : : : : : : : : : : : : : : : : : : : : : : : : : : ATCTCTATGGCCCGAAAAATTGGAGCAAGAGTGTATGCCCTGCCAGAAGACCTGGTTGAAGTGAACCCC $\begin{array}{lllllllllllllllllllllll}I & S & M & A & R & K & I & G & A & R & V & Y & A & I & P & E & D & I & V & E & V & N & P\end{array}$

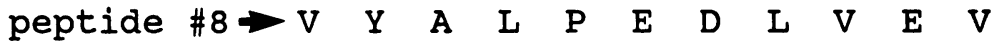

$\begin{array}{lllllllllllllllllllll}K & M & V & M & T & V & F & A & C & L & M & G & R & G & M & K & R & V & & 570\end{array}$ AAGATGGTCATGACTGTGTTTGCATGTTTGATGGGCAGGGGAATGAAGAGAGTGTAA

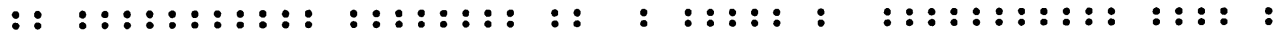
AAAATGGTCATGACCGTGTTTGCCTGCCTCATGGGGAAAGGAATGAAGAGGGTGTGA

$$
\begin{array}{llllllllllllll}
K & M & V & M & T & V & F & A & C & \text { L } & \text { M } & \text { G } & K & \text { G } \\
\text { FIG. } & \text { 2-Continued }
\end{array}
$$

nic substrain of HuT-14 $(19,23)$, was not elevated further in 1-plastin expression (Fig. 4A, lane 5; reference 23). The human fibrosarcoma cell line (HT1080) and leiomyosarcoma cell line (Sarcoma-2) also expressed 1-plastin mRNAs at levels comparable to those of the HuT strains (Fig. 4A, lanes 6 and 7, respectively). These two cell lines were previously shown to express levels of 1-plastin protein comparable to that of the HuT strains (14). The osteogenic sarcoma cell line
HOS synthesizes a low level of 1-plastin which is barely detectable in 2-D gels (14), but 1-plastin mRNA could not be detected in HOS cells by Northern blot analysis (Fig. 4A, lane 8). A second osteogenic sarcoma, MG63, and a retinoblastoma tumor cell line, GM1231A, did not exhibit either the 1-plastin mRNA transcript (Fig. 4A, lanes 13 and 11, respectively) or the 1-plastin polypeptide (data not shown). All of the cell strains listed above expressed relatively 


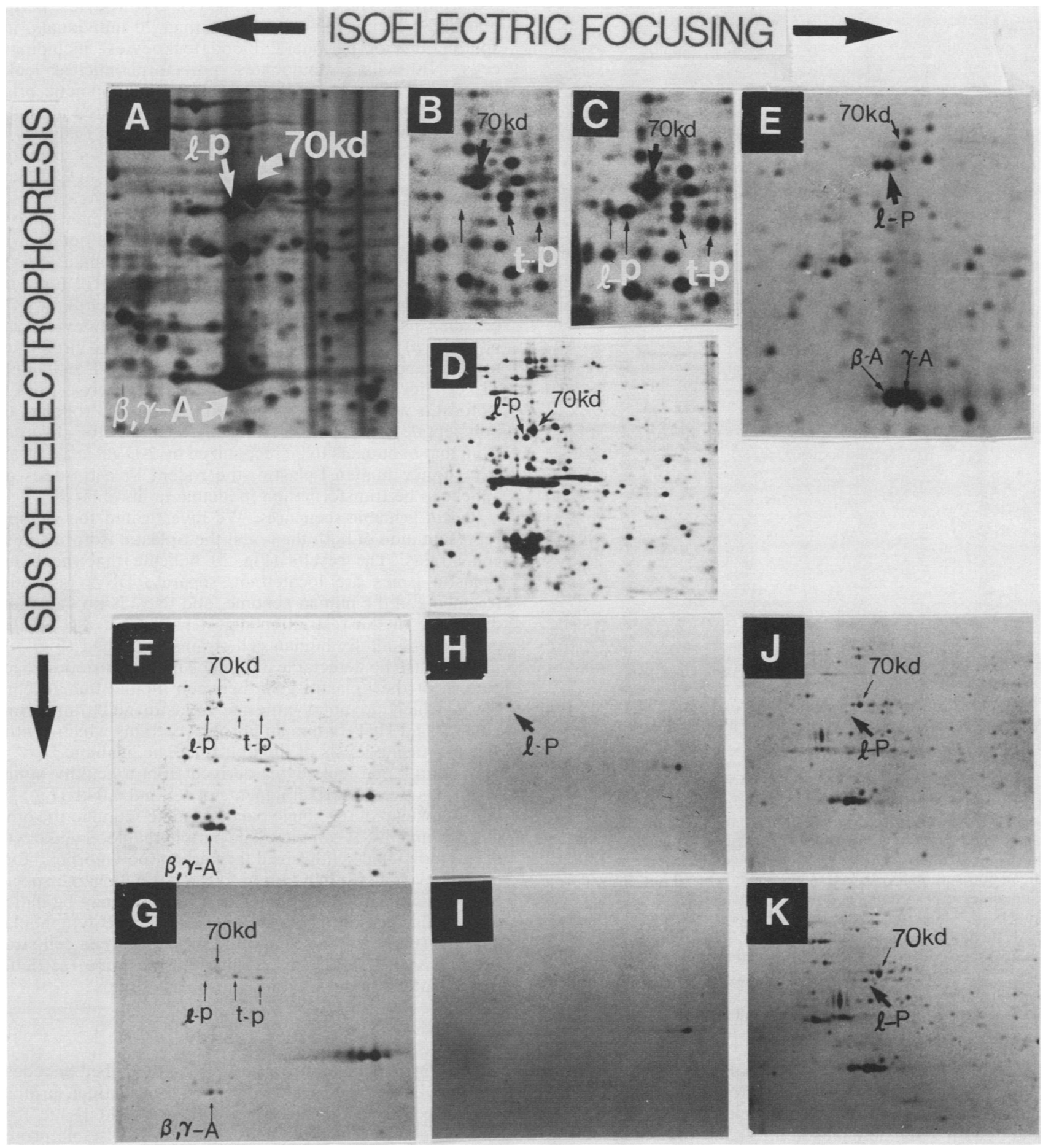

FIG. 3. 2-D gel analysis of cellular proteins and in vitro-translated products. (A) CEM T-lymphoblastoid total cell (ATCC CCL119) unfractionated proteins stained with silver (30); (B) KD untransformed human fibroblast (22) total cell unfractionated proteins labeled with $\left[{ }^{35}\right.$ S]methionine (23); (C) HuT-12 transformed human fibroblasts (22) prepared as in panel B; (D) HuT-14 transformed human fibroblasts (22) prepared as in panel B; (E) normal human monocyte total unfractionated proteins labeled with $\left.{ }^{35} S\right]$ methionine $(13)$; $(F)$ in vitro-translated $\left[{ }^{35}\right.$ S]methionine-labeled polypeptides of total poly(A) ${ }^{+}$mRNA isolated from HuT-14 transformed fibroblasts (25); (G) in vitro-translated polypeptides of poly $(\mathrm{A})^{+}$mRNA from HuT-14 cells used in panel $\mathrm{F}$ and selected by hybridization to the P4 cDNA; (H) in vitro-translated polypeptides of poly $(\mathrm{A})^{+}$mRNA from HuT-14 cells used in panel $\mathrm{F}$ and selected by hybridization to the P107 cDNA; (I) in vitro translation (control) as in panel $\mathrm{H}$, except that no poly $(\mathrm{A})^{+}$mRNA was added to the translation reaction; $(\mathrm{J})$ HuT-12 proteins prepared as in panel $\mathrm{B}$; (K) HuT-12 proteins prepared as in panel B and mixed with in vitro-translated polypeptides prepared as in panel H. Abbreviations: $\beta$-A, $\beta$-actin; $\gamma$-A, $\gamma$-actin; l-P, l-plastin; t-P, t-plastin; $70 \mathrm{kd}$, ubiquitous 70-kilodalton polypeptide; SDS, sodium dodecyl sulfate. 


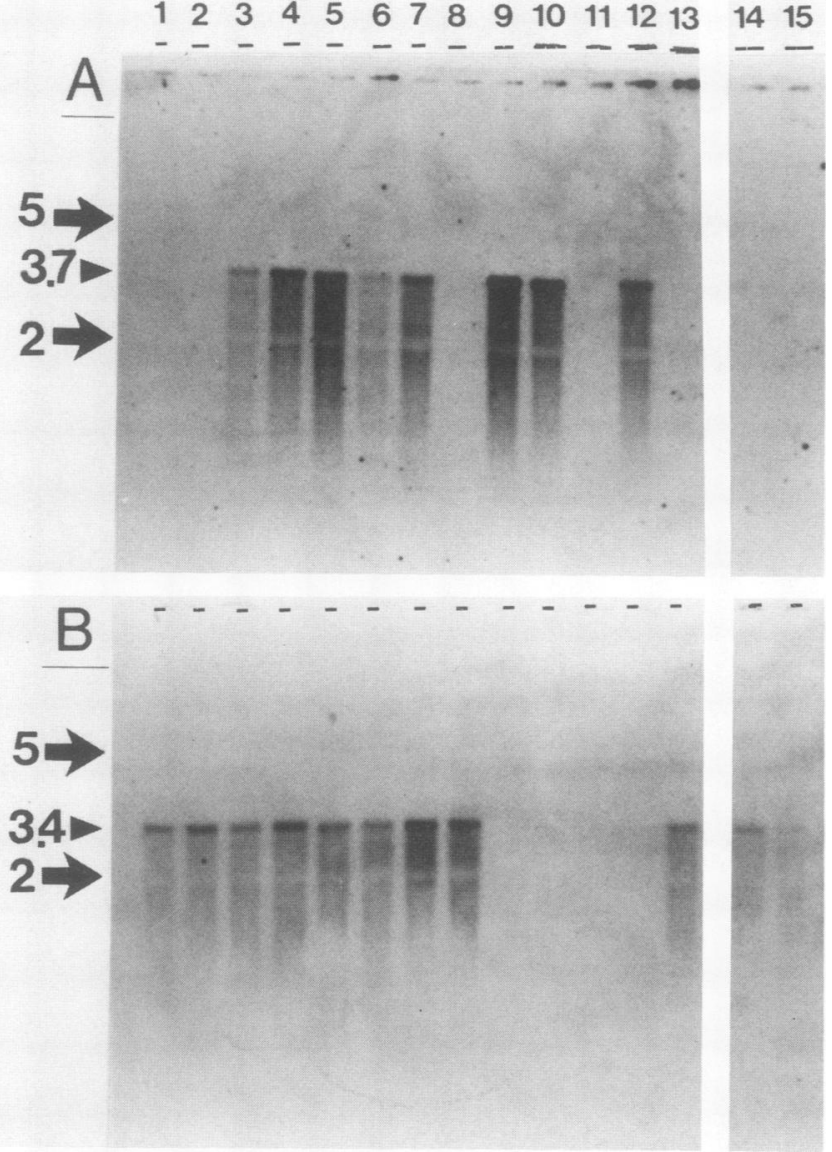

FIG. 4. Northern analysis of plastin expression. Two identical Northern blots (A and B) were hybridized with ${ }^{32}$ P-labeled cDNAs of P107 and P4, respectively. Each blot contains cellular RNAs of the following cell strains: lane $1, \mathrm{KD}$, untransformed human fibroblasts (22); lane 2, R17, untransformed human fibroblasts provided by Thomas Hassel, University of North Carolina, Chapel Hill; lane 3 , HuT-12, transformed human fibroblasts (22); lane 4, HuT-14, transformed, tumorigenic human fibroblasts (22); lane 5, HuT-14T, transformed, tumorigenic human fibroblasts (22); lane 6, HT1080, human fibrosarcoma (14); lane 7, Sarcoma-2, a cell line derived from a human leiomyosarcoma and provided by George Milo, Ohio State University, Columbus; lane 8, HOS, osteosarcoma (14); lane 9, CEM, human T-cell leukemia (2), ATCC CCL119; lane 10, AG1484 B-lymphoblast strain from the Mutant Human Genetic Cell Repository, Camden, N.J.; lane 11, GM1231A retinoblastoma strain; lane 12, Molt-4 (20), T-cell leukemia; lane 13, MG63 osteogenic sarcoma, ATCC CRL1427; lane 14, Rat-2 (19); and lane 15, 3T3 (19).

constant levels of t-plastin mRNA transcripts (Fig. 4B, lanes 1 through 8 and 13) and polypeptides (examples shown in Fig. 3B and C) except for the retinoblastoma cell line, which exhibited no detectable plastin mRNA or protein at all (Fig. $4 \mathrm{~A}$ and $\mathrm{B}$, lane 11; 2-D gel data not shown).

Expression of plastin isoforms in human leukocytes. The three lymphocyte cell lines, CEM and Molt-4 (both T-cell leukemias) and AG1484, a transformed B-lymphoblast cell line, synthesized high levels of l-plastin mRNA (Fig. 4A, lanes 9,10 , and 12 , respectively), but no detectable t-plastin mRNA (Fig. 4B, lanes 9, 10, and 12, respectively). Leukemic cell lines such as CEM (Fig. 3A) and normal leukocytes such as peripheral blood leukocytes (13) and cultured monocytes (Fig. 3E) synthesize the highest levels of 1-plastin protein (13), but no t-plastin protein (Fig. 3A and E). We examined more than 20 different lymphoblastoid cell lines, the promyelocytic cell line HL-60 (4), erythrocytes, peripheral blood leukocytes from more than 20 individuals, and subfractions of peripheral blood leukocytes, including $T$ cells, NK cells, granulocytes, polymorphonuclear leukocytes, and monocytes (13). All cells of hemopoietic origin except fully differentiated erythrocytes exhibited abundant synthesis of l-plastin (13) and failed to express t-plastin.

Plastin expression in rodent cells. Finally, we examined two widely cultured rodent fibroblast strains, Rat-2 (21) and mouse $3 T 3(6,21,36)$, and found that both synthesize plastins and mRNA corresponding to the human t-plastin isoform (Fig. 4A, lanes 14 and 15; 2-D gel data not shown). We also detected mRNA corresponding to human 1-plastin mRNA in mouse B-cell lymphoma cell line M12 (data not shown). However, we have not been able to identify, by 2-D gel analysis, 1-plastin isoform in mouse lymphocytes (data not shown) or ras-transformed, herpes simplex virus-transformed, and spontaneously transformed Rat-2 and mouse 3T3 cell lines (21). We have concluded that whereas t-plastin isoform is well conserved between humans and rodents, the polypeptide of 1-plastin isoform of rodents is too divergent from that of humans to be recognized by 2-D gel analysis and that, unlike human 1-plastin, the rodent 1-plastin does not appear to be transformation inducible in fibroblasts.

Plastin genomic sequences. We investigated the genomic representation of both the 1 - and the $t$-plastin isoforms in six cell strains. The results (Fig. 5) indicate that the $1-$ and t-plastin genes are located on separate DNA restriction fragments in the human genome, and there is no detectable difference in the restriction digest pattern of the t-plastin gene among all six human cell strains examined (Fig. 5A). There is also no detectable difference in the restriction digest pattern of the 1-plastin gene between diploid human fibroblasts which do not synthesize l-plastin and transformed HuT-12 and HuT-14 human fibroblast strains which synthesize increasing levels of the 1-plastin. The genomic DNA of peripheral blood leukocytes derived from a healthy human donor has two HindIII fragments of 6.5 and $6.0 \mathrm{~kb}$ (Fig. 5B, lane 4) instead of the single band of $6.5 \mathrm{~kb}$ found in the other five genomic DNA samples. The peripheral blood leukocytes of this individual synthesized the variant (polymorphic) form of the l-plastin (13) in addition to the normal-charge species of 1-plastin. The $6.0-\mathrm{kb}$ fragment, therefore, may be indicative of this variant form of l-plastin. The B-lymphoblast AG1484 (Fig. 5B, lane 5) and the retinoblastoma cell strain GM1231A (Fig. 5B, lane 6) exhibited the same restriction digest pattern as did the three fibroblast strains.

\section{DISCUSSION}

The plastin gene family that we have described encodes a truly novel set of at least two related, but distinct, proteins whose expression distinguishes cells of solid tissue from hemopoietic or leukocyte cells. 1-Plastin is a stable protein that is synthesized constitutively at a very high rate in a majority of subtypes of peripheral blood leukocytes and is one of the 10 or 20 most abundant proteins of these normal leukocyte cells. t-Plastin currently defines two equally abundant polypeptide species in fibroblasts, epithelial, and endothelial cells that appear to have the same molecular weight as l-plastin, but they are slightly more basic. Our current results do not establish whether the two t-plastin isoforms differ from each other because of differing posttranslational modification or because they are encoded by separate mRNAs or genes. 


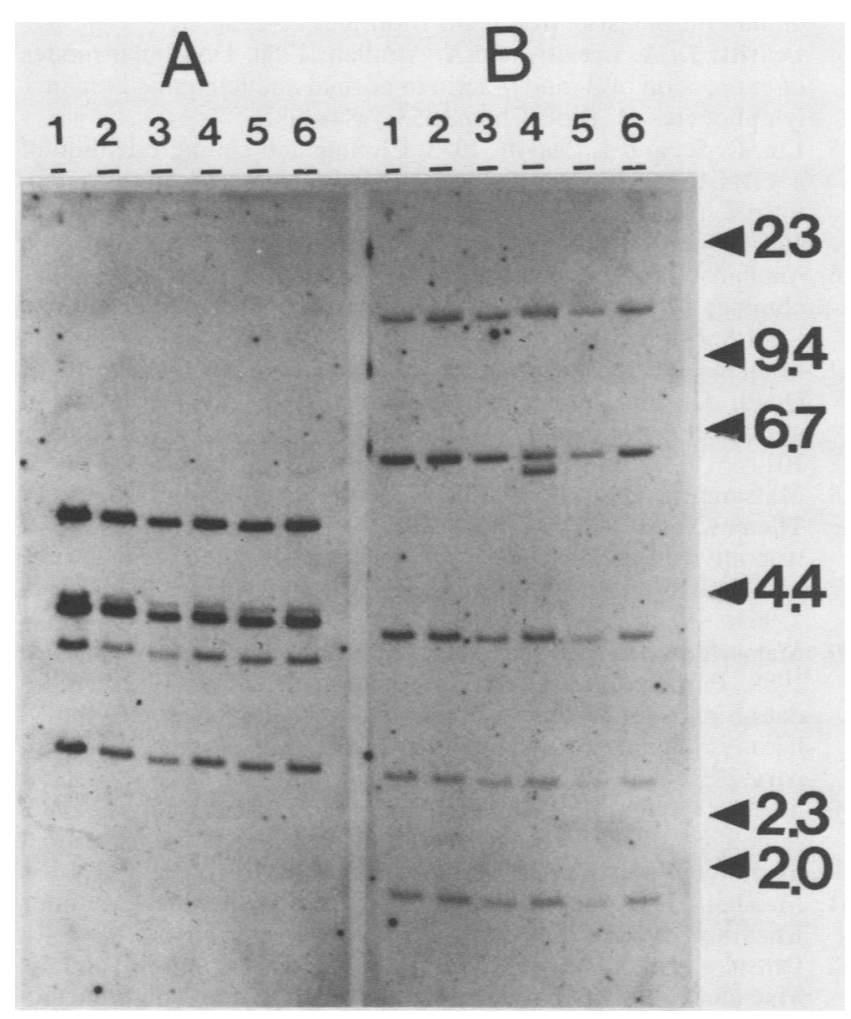

FIG. 5. Genomic representation of plastin genes. Two identical genomic blots (A and B) were hybridized with ${ }^{32} \mathrm{P}$-labeled cDNAs of P4 and P107, respectively. Each blot contains HindIII-digested genomic DNAs of KD (lane 1), HuT-12 (lane 2), HuT-14 (lane 3), peripheral blood lymphocytes (lane 4), B-lymphoblast strain AG1484 (lane 5), and retinoblastoma tumor cell strain GM1231A (lane 6). Size markers on the right are HindIII fragments of phage $\lambda$ DNA. All human cell strains are described in the legend to Fig. 4.

The divergence of $\mathrm{l}$ - and $\mathrm{t}$-plastin is striking because these two proteins, though they are clearly related, have diverged by $17 \%$ of their amino acids, with these replacements scattered almost randomly throughout the 570 amino acid residues of the plastin sequence. Thirty-three percent of these amino acid exchanges involve charged amino acid replacements, with seven short peptide domains exhibiting significantly greater divergence (residues 1 to 12 [50\%], residues 18 to 30 [58\%], residues 224 to 230 [57\%], residues 258 to 275 [50\%], residues 449 to 459 [50\%], residues 487 to 496 [50\%], and residues 512 to 523 [58\%]).

We scanned three protein sequence data bases (EMBL, National Institutes of Health, and another one compiled by Russell Doolittle, University of California, San Diego) for sequences that were related to plastin and found that no related protein or peptide sequence has yet been cataloged. Recently, Matsushima et al. (29) reported the purification and characterization of a cytosolic 65-kilodalton phosphoprotein in human leukocytes. This protein is clearly l-plastin because a sequence of 22 amino acids (29) is identical to the amino acid sequence of 1-plastin between residues 533 and 554 (Fig. 2). Their characterization of this protein as a highly abundant, N-blocked phosphoprotein of all major leukocyte subpopulations which is not expressed in normal human fibroblasts or HeLa cells is consistent with our findings presented here and in other publications $(13,18)$. Furthermore, their finding that 1 -plastin is phosphorylated at serine residues is consistent with the results of Anderson et al. (4).
Finally, it should be pointed out that the induction of 1-plastin expression in human fibroblasts does not appear to correlate with the activation of known oncogenes since the HuT strains, which lack detectable oncogenes that will transform 3T3 cells (5; unpublished results), and HT1080 cells, which have an activated N-ras oncogene (33), both abundantly express l-plastin. This lack of correlation with oncogene activation is also characteristic of the actin and tropomyosin gene families in response to neoplastic transformation $(6,9,16,21,28,38)$. Plastin, actin, and tropomyosin are all highly abundant cellular proteins that have differentiation-specific isoforms. Their involvement in both tissue differentiation and neoplastic transformation is consistent with the notion that genes that play critical roles in oncogenesis are often important constituents in the normal development of tissues.

\section{ACKNOWLEDGMENTS}

Most of the work performed by C.-S.L., M.V., and J.L. was carried out at the Linus Pauling Institute, Palo Alto, Calif. We thank Sandra Schwoebel (Linus Pauling Institute) for help in the preparation of this manuscript and Wade Hines (California Institute of Technology) for expert technical assistance.

This work was supported by Public Health Service grant CA34763 (to J.L.) from the National Institutes of Health and by grants from the Biological Instrumentation Division of the National Science Foundation and the Monsanto Corporation. R.H.A. was the recipient of a fellowship from the Swiss National Science Foundation.

\section{LITERATURE CITED}

1. Aebersold, R. H., J. Leavitt, L. E. Hood, and S. B. H. Kent. 1987. Sequencing of proteins after separation in polyacrylamide gels, p. 277-294. In K. Walsh (ed.), Methods in protein sequence analysis. Humana Press, Clifton, N.J.

2. Aebersold, R. H., J. Leavitt, R. A. Saavedra, L. E. Hood, and S. B. H. Kent. 1987. Internal amino acid sequence analysis of proteins separated by one- and two-dimensional gel electrophoresis after in situ protease digestion on nitrocellulose. Proc. Natl. Acad. Sci. USA 84:6970-6974.

3. Aebersold, R. H., D. B. Teplow, L. E. Hood, and S. B. H. Kent. 1986. Electroblotting onto activated glass: high efficiency preparation of proteins from analytical SDS-polyacrylamide gels for direct sequence analysis. J. Biol. Chem. 261:4229-4243.

4. Anderson, N. L., M. A. Gemmell, P. M. Coussens, S.-I. Murao, and E. Huberman. 1985. Specific protein phosphorylation in human promyelocytic HL-60 leukemia cells susceptible or resistant to induction of cell differentiation by phorbol-12-myristate-13-acetate. Cancer Res. 45:4995-5003.

5. Cooper, C. S., D. G. Blair, M. K. Oskarsson, M. A. Tainsky, L. A. Eader, and G. F. Vande Woude. 1984. Characterization of human transforming genes from chemically transformed, teratocarcinoma, and pancreatic carcinoma cell lines. Cancer Res. 44:1-10.

6. Cooper, H. L., N. Feuerstein, M. Noda, and R. H. Bassin. 1985. Suppression of tropomyosin synthesis, a common biochemical feature of oncogenesis, by structurally diverse retroviral oncogenes. Mol. Cell. Biol. 5:972-983.

7. Dale, R. M., B. A. McClure, and J. P. Houchins. 1985. A rapid single-stranded cloning strategy for producing a sequential series of overlapping clones for use in DNA sequencing: application to sequencing the corn mitochondrial 18S rDNA. Plasmid 13:31-40.

8. Denhardt, D. T. 1966. A membrane filter technique for the detection of complementary DNA. Biochem. Biophys. Res. Commun. 23:641-646.

9. Franza, B. R., and J. I. Garrels. 1984. Transformation-sensitive proteins of REF52 cells detected by computer-analyzed two dimensional gel electrophoresis. Cancer Cells 1:137-146.

10. Goldman, D., L. R. Goldin, P. Rathnagiri, S. J. O'Brien, J. A. 
Egeland, and C. R. Merril. 1985. Twenty-seven protein polymorphisms detected by two-dimensional electrophoresis of serum, erythrocytes, and fibroblasts in two pedigrees. Am. J. Hum. Genet. 37:898-911.

11. Goldman, D., and C. R. Merril. 1983. Human lymphocyte polymorphisms detected by quantitative two-dimensional electrophoresis. Am. J. Hum. Genet. 35:827-837.

12. Goldman, D., C. R. Merril, R. J. Polinsky, and M. H. Ebert. 1982. Lymphocyte proteins in Huntington's disease: quantitative analysis by use of two-dimensional electrophoresis of proteins and computerized microdensitometry. Clin. Chem. 28: 1021-1025.

13. Goldstein, D., J. Djeu, G. Latter, S. Burbeck, and J. Leavitt. 1985. Abundant synthesis of the transformation-induced protein of neoplastic human fibroblasts, plastin, in normal lymphocytes. Cancer Res. 45:5643-5647.

14. Goldstein D., and J. Leavitt. 1985. Expression of neoplasiarelated proteins of chemically transformed HuT fibroblasts in human osteosarcoma HOS fibroblasts and modulation of actin expression upon elevation of tumorigenic potential. Cancer Res. 45:3256-3261.

15. Gunning, P., T. Mohun, S.-Y. Ng, P. Ponte, and L. Kedes. 1984. Evolution of the human sarcomeric-actin genes: evidence for units of selection within the $3^{\prime}$ untranslated regions of the mRNAs. J. Mol. Evol. 20:202-214.

16. Hendricks, M., and H. Weintraub. 1981. Tropomyosin is decreased in transformed cells. Proc. Natl. Acad. Sci. USA 78: 5633-5637.

17. Kent, S. B. H., L. E. Hood, R. Aebersold, D. Teplow, L. Smith, W. Hines, V. Farnsworth, P. Cartier, P. Hughes, and C. Dodd. 1987. Approaches to subpicomole protein sequencing. Bio/ Technology 5:314-321.

18. Kondo, L., and H. Hamaguchi. 1986. Evidence for the close linkage between lymphocyte cytosol polypeptide with molecular weight of 64,000 LCP1 and esterase D. Am. J. Hum. Genet. 37:1106-1111.

19. Leavitt, J., G. Bushar, T. Kakunaga, H. Hamada, T. Hirakawa, D. Goldman, and C. Merril. 1982. Variations in expression of mutant $\beta$-actin accompanying incremental increases in human fibroblast tumorigenicity. Cell 28:259-268.

20. Leavitt, J., D. Goldman, C. Merril, and T. Kakunaga. 1982. Changes in gene expression accompanying chemically-induced malignant transformation of human fibroblasts. Carcinogenesis 3:61-70.

21. Leavitt, J., P. Gunning, L. Kedes, and R. Jariwalla. 1985 Smooth muscle $\alpha$-actin is a transformation-sensitive marker for mouse NIH 3T3 and Rat-2 cells. Nature (London) 316:840-842.

22. Leavitt, J., and T. Kakunaga. 1980. Expression of a variant form of actin and additional polypeptide changes following chemicalinduced in vitro neoplastic transformation of human fibroblasts. J. Biol. Chem. 255:1650-1661.

23. Leavitt, J., G. Latter, L. Lutomski, D. Goldstein, and S. Burbeck. 1986. Tropomyosin isoform switching in tumorigenic human fibroblasts. Mol. Cell. Biol. 6:2721-2726.

24. Leavitt, J., A. Leavitt, and A. Attallah. 1980. Dissimilar modes of expression of $\beta$ - and $\gamma$-actin in normal and leukemic human T lymphocytes. J. Biol. Chem. 255:4984-4987.

25. Lin, C.-S., and J. Leavitt. 1988. Cloning and characterization of a cDNA encoding transformation-sensitive tropomyosin isoform 3 from tumorigenic human fibroblasts. Mol. Cell. Biol. 8: 160-168.

26. Maniatis, T., E. F. Fritsch, and J. Sambrook. 1982. Molecular cloning, a laboratory manual. Cold Spring Harbor Laboratory, Cold Spring Harbor, N.Y.

27. Maniatis, T., R. Hardison, E. Lacy, J. Lauer, C. O'Connell, D. Quan, G. Sim, and A. Efstratiadis. 1978. The isolation of structural genes from libraries of eukaryotic DNA. Cell 15:687701.

28. Matsumura, F., J. J.-C. Lin, S. Yamashiro-Matsumura, G. P. Thomas, and W. C. Topp. 1983. Differential expression of tropomyosin forms in the microfilaments isolated from normal and transformed rat cultured cells. J. Biol. Chem. 258:13954 13964.

29. Matsushima, K., M. Shiroo, H.-F. Kung, and T. D. Copeland. 1988. Purification and characterization of a cytosolic 65-kilodalton phosphoprotein in human leukocytes whose phosphorylation is augmented by stimulation with interleukin 1. Biochemistry 27:3765-3770.

30. Merril, C. R., D. Goldman, and M. L. Van Keuren. 1982. Simplified silver protein detection and image enhancement methods in polyacrylamide gels. Electrophoresis 3:17-23.

31. Messing, J. 1983. New M13 vectors for cloning. Methods Enzymol. 101:20-78.

32. Ohtsuka, E., S. Matsuki, M. Ikehora, Y. Takahashi, and $K$. Matsubaro. 1985. An alternative approach to deoxyoligonucleotides as hybridization probes by insertion of deoxyinosine at ambiguous codon positions. J. Biol. Chem. 260:2605-2608.

33. Paterson, H., B. Reeves, R. Brown, A. Hall, M. Furth, J. Bos, P. Jones, and C. Marshall. 1987. Activated N-ras controls the transformed phenotype of HT1080 human fibrosarcoma cells. Cell 51:803-812.

34. Sanger, F., S. Nicklen, and A. R. Coulsen. 1977. DNA sequencing with chain-terminating inhibitors. Proc. Natl. Acad. Sci. USA 74:5463-5467.

35. Southern, E. M. 1975 . Detection of specific sequences among DNA fragments separated by gel electrophoresis. J. Mol. Biol. 98:503-517.

36. Tabin, C. J., S. M. Bradley, C. I. Bargmann, R. A. Weinberg, A. G. Papageorge, E. M. Scolnick, R. Dahr, D. R. Lowy, and E. H. Chang. 1982. Mechanism of activation of a human oncogene. Nature (London) 300:143-149.

37. Varma, M., U. Aebi, J. Fleming, and J. Leavitt. 1987. A 60-kd polypeptide in mammalian cells with epitopes related to actin. Exp. Cell Res. 173:163-173.

38. Witt, D. P., D. J. Brown, and J. A. Gordon. 1983. Transformation-sensitive isoactin in passaged chick embryo fibroblasts transformed by Rous sarcoma virus. J. Cell Biol. 96:1766-1771. 